\title{
Study of MEH-PPV/PCBM active layer morphology and its application for hybrid solar cell performance
}

\author{
QUYNH NHU NGUYEN TRUONG, NGUYEN TAM NGUYEN TRUONG, CHINHO PARK and \\ JAE HAK JUNG* \\ School of Display and Chemical Engineering, Yeungnam University, 214-1 Dae-dong, Gyeongsan 712-749, \\ Republic of Korea
}

MS received 29 December 2010; revised 12 March 2011

\begin{abstract}
Surface morphologies of MEH-PPV:PCBM active layers were optimized by investigating ITO substrate treated with oxygen and nitrogen plasma. This treatment effectively improved smoothness, transmittance, and contact angle of ITO's, resulting in good anode contacts for hybrid device structures. The consistently improved performance of hybrid solar cells was also achieved. The surface properties of treated and untreated ITO substrates were compared by contact angle, four point probe, scanning electron microscopy, and atomic force microscopy.
\end{abstract}

Keywords. Plasma treatment; hybrid; anode; cathode; indium tin oxide (ITO); surface roughness.

\section{Introduction}

Due to the crises surrounding conventional energy sources, electrical energy from solar cell is gaining importance. Therefore, study of hybrid polymer solar cells is becoming a popular occupation for many engineers and researchers because of its low cost, simple processing, and promising technological applications (Gur et al 2007; Ayzner et al 2008; Tang et al 2008). They can easily reach $4 \%$ power conversion efficiency (Li et al 2005; Reyes et al 2005), with 6\% being the maximum reported (Kim et al 2007) from a method that allows solution processing of all the active layers. Solubility is important to allow the deposition of organic layers by either spray deposition or injection printing.

The improvement of hybrid solar cells' performance has been suggested by optimizing processing parameters such as solvent, solvent drying conditions, and electron donor to acceptor ratio. However, $\mathrm{P}_{3} \mathrm{HT}$ and $\mathrm{PCBM}$ with a ratio of 1:0.7 has been reported best for device performance (Jin et al 2007), and performance improvement by controlling morphology of the $\mathrm{P}_{3} \mathrm{HT} / \mathrm{PCBM}$ active layer can be more easily achieved by the appropriate selection of solvents (Koetniyom et al 2010). The blended MEH-PPV/ PCBM hybrid solar cells structure can reach up to $3.9 \%$ power conversion efficiency (Deng et al 2001). Therefore, device performance is likely to be enhanced by optimizing both the MEH-PPV: PCBM ratio and the active layer thickness (Breeze et al 2001).

The choice of anode, from the many viable candidates, is also important to the improvement of solar cells. However, the most commonly used is an indium tin oxide (ITO)/glass substrate. ITO is also most commonly used in organic light

\footnotetext{
*Author for correspondence (jhjung@ynu.ac.kr)
}

emitting diodes (OLEDs) because it is a highly degenerate $n$-type semiconductor with low resistance and high transmittance in the visible spectrum. Changing ITO's properties will influence device performance. The effects of different surface treatments (e.g. plasma treatment, annealing process, ultraviolet-ozone (UV-ozone), and self-assembled monolayers, SAMs) on ITO's properties and OLEDs' performance have been extensively investigated (Jeong et al 2006; You and Dong 2006; Kim et al 2007, 2008). However, effects of treatments on hybrid solar cells' performance have not been similarly investigated, despite their likely beneficial effects (Kim et al 2007): surface treatment can significantly enhance work function, carrier concentration and mobility.

In this study, optimization of active layer surface morphology was studied with respect to oxygen and nitrogen plasma treatments of the ITO's surface in glass/ITO/PEDOT: PSS/MEH-PPV:PCBM composite film. The effect of plasma treatment on the properties of ITO's surface was determined by atomic force microscopy (AFM), scanning electron microscopy (SEM), and a video contact angle system (VCAS). Finally, the hybrid solar cells structure as glass/ITO/PEDOT:PSS/MEH-PPV: PCBM/Al was fabricated and characterized by using an AM 1.5 solar-simulator.

\section{Experimental}

Regioregular poly[2-methoxy, 5-(2'-ethylhexyloxy)-1,4phenylene-vinylene] (MEH-PPV) and [6,6]-phenylen $\mathrm{C}_{61}$-butyric acid methyl ester $(\mathrm{PCBM})$ were purchased from Sigma-Aldrich. Hybrid solar cells were fabricated with ITO/PEDOT: PSS/(MEH-PPV+ PCBM)/Al structures, where MEH-PPV and PCBM were the electron donor and acceptor, respectively. A $180 \mathrm{~nm}$ ITO film with a sheet 


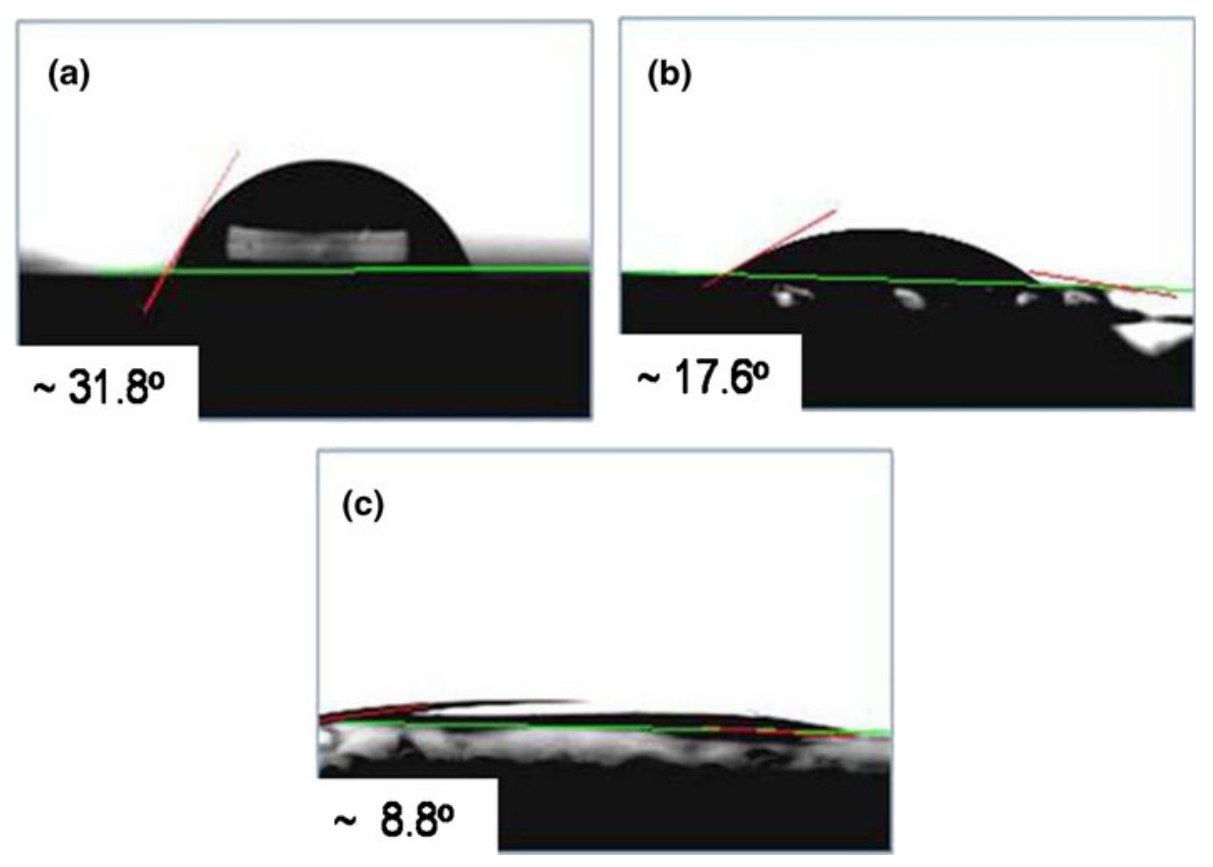

Figure 1. Contact angles of ITO anodes: (a) untreated, (b) oxygen-plasma treated and (c) nitrogen-plasma treated.

resistance of $9.2 \Omega / \mathrm{sq}$ was used as anode of these photovoltaic devices. ITO glasses were cleaned by sequential ultrasonification in trichloroethylene, acetone, and methanol solvents for a total of $30 \mathrm{~min}$. They were then dried under a nitrogen flow. ITO surfaces were then treated by plasma in a nitrogen chamber at $100 \mathrm{~W}, 200 \mathrm{mTorr}$ for $10 \mathrm{~min}$. Furthermore, a thin layer of polyethylene dioxythiophene doped with polystyrene-sulfonic acid (PEDOT:PSS, Sigma Aldrich) was spin-coated at $4000 \mathrm{rpm}$ for $30 \mathrm{~s}$ on the cleaned ITO-coated glass substrate. Typical thicknesses of $70 \mathrm{~nm}$ resulted. The thin layers were then dried at $100{ }^{\circ} \mathrm{C}$ for $30 \mathrm{~min}$. Spin-coating for photoactive layer deposition was kept at $3000 \mathrm{rpm}$ to obtain a smoother surface with $150 \mathrm{~nm}$ active layer thickness. A $90 \mathrm{~nm} \mathrm{Al}$ cathode layer was deposited on the active layer by thermal evaporation in a vacuum chamber at $2.2 \times 10^{-6}$ Torr, which was prepared from a MEH-PPV: PCBM composite solution.

The properties of plasma treatment on ITO surface morphology were observed using a four-point probe, atomic force microscopy (AFM, NanoScope IIIa), and scanning electron microscopy (SEM, S-4100). In addition, the solar cell characteristics were also evaluated using a solar simulator (Keithley 69911) with AM 1.5 illumination.

\section{Results and discussion}

The optical microscopic images of the water contact angle with untreated, $\mathrm{O}_{2}$ treated, and $\mathrm{N}_{2}$ treated ITO are shown in figure 1. Average contact angles were calculated from measurements taken at three positions on each sample. They were $31.8^{\circ}$ for untreated, $17.6^{\circ}$ for $\mathrm{O}_{2}$ treated, and $8.8^{\circ}$ for $\mathrm{N}_{2}$ treated ITO, demonstrating that ITO's surface was significantly improved, becoming uniform and smoother after the $\mathrm{N}_{2}$ plasma treatment. We suggested more energetic surface, as well as the potential to support higher quality thin films.

Water contact angles of these films and their surface roughness, observed by AFM, are listed in table 1. The effects of plasma treatment on the electrical resistivity of ITO surfaces were measured by a four-point probe. The sheet resistance of untreated, $\mathrm{O}_{2}$ treated and $\mathrm{N}_{2}$ treated ITO was found to be $9.2,8.5$ and $7.9(\Omega / \mathrm{sq})$. The resistivity of untreated, $\mathrm{O}_{2}$ treated, and $\mathrm{N}_{2}$ treated ITO was found to be $5.52 \times 10^{-5} \Omega . \mathrm{cm}, 4.83 \times 10^{-5} \Omega . \mathrm{cm}$ and $4.78 \times$ $10^{-5} \Omega . \mathrm{cm}$, respectively. Nitrogen plasma treatment resulted in ITO with a slightly lower resistivity than the other tested substrates. Hence, it can significantly contribute to increasing the conductivity of ITO films.

Table 1. Surface characteristics of untreated, $\mathrm{O}_{2}$ and $\mathrm{N}_{2}$ plasma treated ITO glass.

ITO anode RMS roughness $(\mathrm{nm})$ Water contact angle $(0)$ Sheet resistance $(\Omega / \mathrm{sq})$ Resistivity $(\Omega . \mathrm{cm})$

\begin{tabular}{lcccc}
\hline Untreated & 4.26 & 31.8 & 9.2 & $5.5 \times 10^{-5}$ \\
$\mathrm{O}_{2}$ Plasma & 2.89 & 17.6 & 8.5 & $4.83 \times 10^{-5}$ \\
$\mathrm{~N}_{2}$ Plasma & 2.19 & 8.8 & 7.9 & $4.78 \times 10^{-5}$ \\
\hline
\end{tabular}


Figure 2 shows AFM topography images of ITO surface roughness before and after treatment. The surface roughness of untreated, $\mathrm{O}_{2}$ treated, and $\mathrm{N}_{2}$ treated ITO were 4.26, 2.89 and $2.19 \mathrm{~nm}$, respectively, demonstrating that $\mathrm{N}_{2}$ plasma treatment more effectively smoothed the ITO surface than oxygen plasma treatment, a finding consistent with other works (Kim et al 2008; Afre et al 2009). ITO surface roughness affects the roughness of layers subsequently deposited upon it. It also affects their charge mobility, and the cell's efficiency. Therefore, $\mathrm{N}_{2}$ plasma treatment is a useful process for the preparation of ITO for use in solar cells.

To evaluate the effect of plasma treatment on the morphology of the ITO/PEDOT:PSS/(PCBM+MEH:PPV) active layer, atomic force microscopy (AFM) and scanning electron microscopy (SEM) were carried out and are shown in figure 3. RMS surface roughness of films coated onto the ITO substrate decreased with plasma treatment, more so for treatment with $\mathrm{N}_{2}$ than with $\mathrm{O}_{2}$. The SEM image of these films on the untreated ITO depicts large islands on the top surface, clearly showing non-uniformity of the active layer's surface.
However, film deposited on nitrogen-treated ITO substrate shows the smallest islands and is uniform in comparison with the untreated and oxygen plasma-treated films.

Figure 4 shows $I-V$ curves of devices made with untreated, oxygen-treated, and nitrogen-treated ITO at room temperature. The open circuit voltages $\left(V_{\mathrm{oc}}\right)$ of the samples, short circuit current densities $\left(J_{\mathrm{sc}}\right)$, fill factors $(\mathrm{FF})$ and power conversion efficiencies $(\eta)$ are listed in table 2 . The cell with nitrogen-treated ITO had the best values of these properties, i.e. $V_{\mathrm{oc}}=0.7 \mathrm{~V}, J_{\mathrm{sc}}=4.59 \mathrm{~mA} / \mathrm{cm}^{2}, \mathrm{FF}=0.7$, and $\eta=$ $2 \cdot 25 \%$. Improved chemical stability, smoother surfaces, and enhanced work functions of thin films have all been reported of $\mathrm{N}_{2}$ plasma treatment (Kim et al 2008). The $I-V$ curves of the cells show series resistance to be significantly reduced by plasma treatment. Also the smoother active layers' surfaces improved charge carrier transport. We conclude that the ITO/PEDOT:PSS/(PCBM+MEH:PPV) active layer surface morphology would be optimized by plasma treated on ITO surface. The ITO treated by $\mathrm{N}_{2}$ plasma was shown to be better than untreated ITO and that treated by $\mathrm{O}_{2}$ plasma.
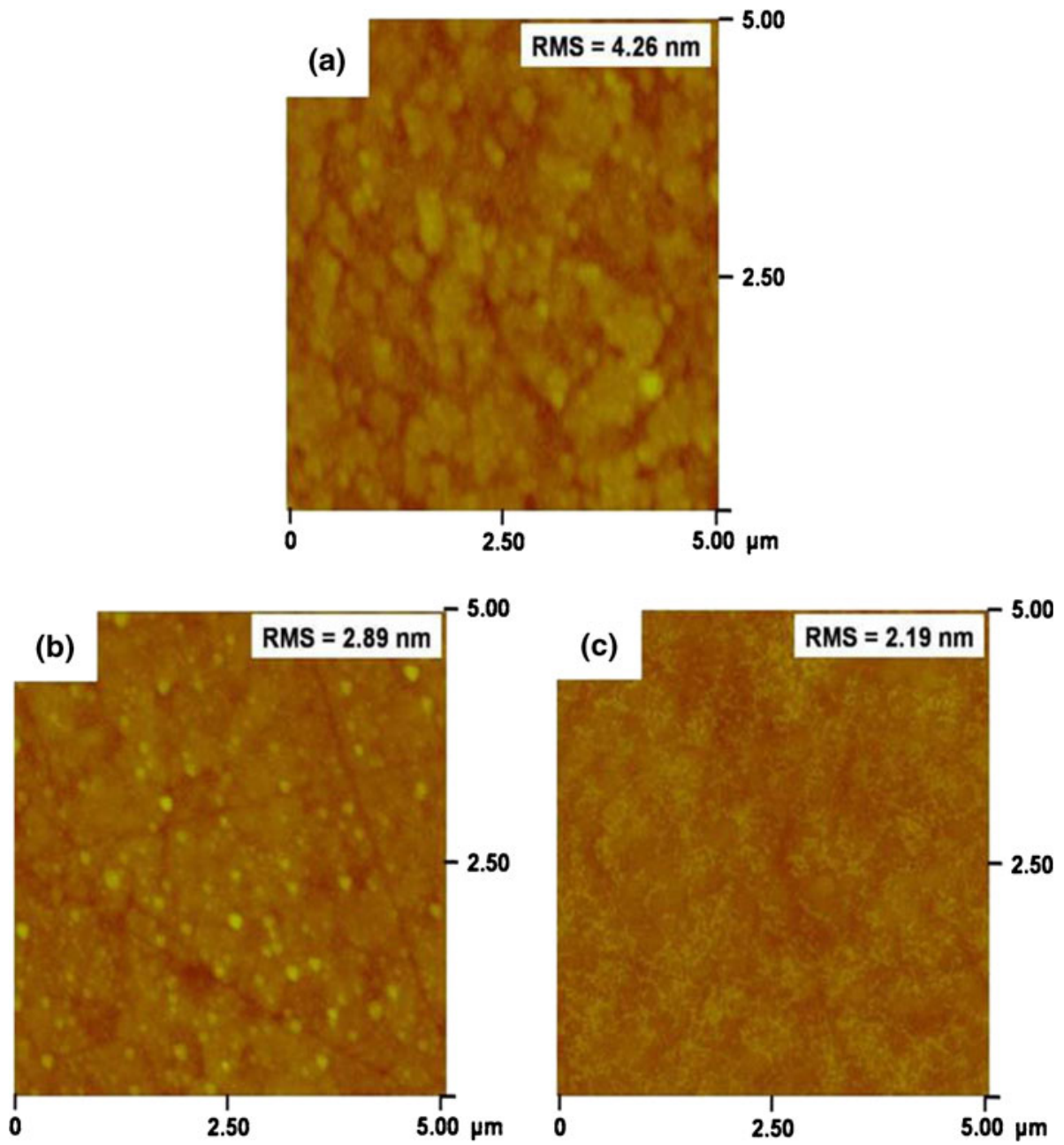

Figure 2. Surface roughness (AFM) images of ITO anodes: (a) untreated, (b) oxygen-plasma treated, and (c) nitrogen-plasma treated. 

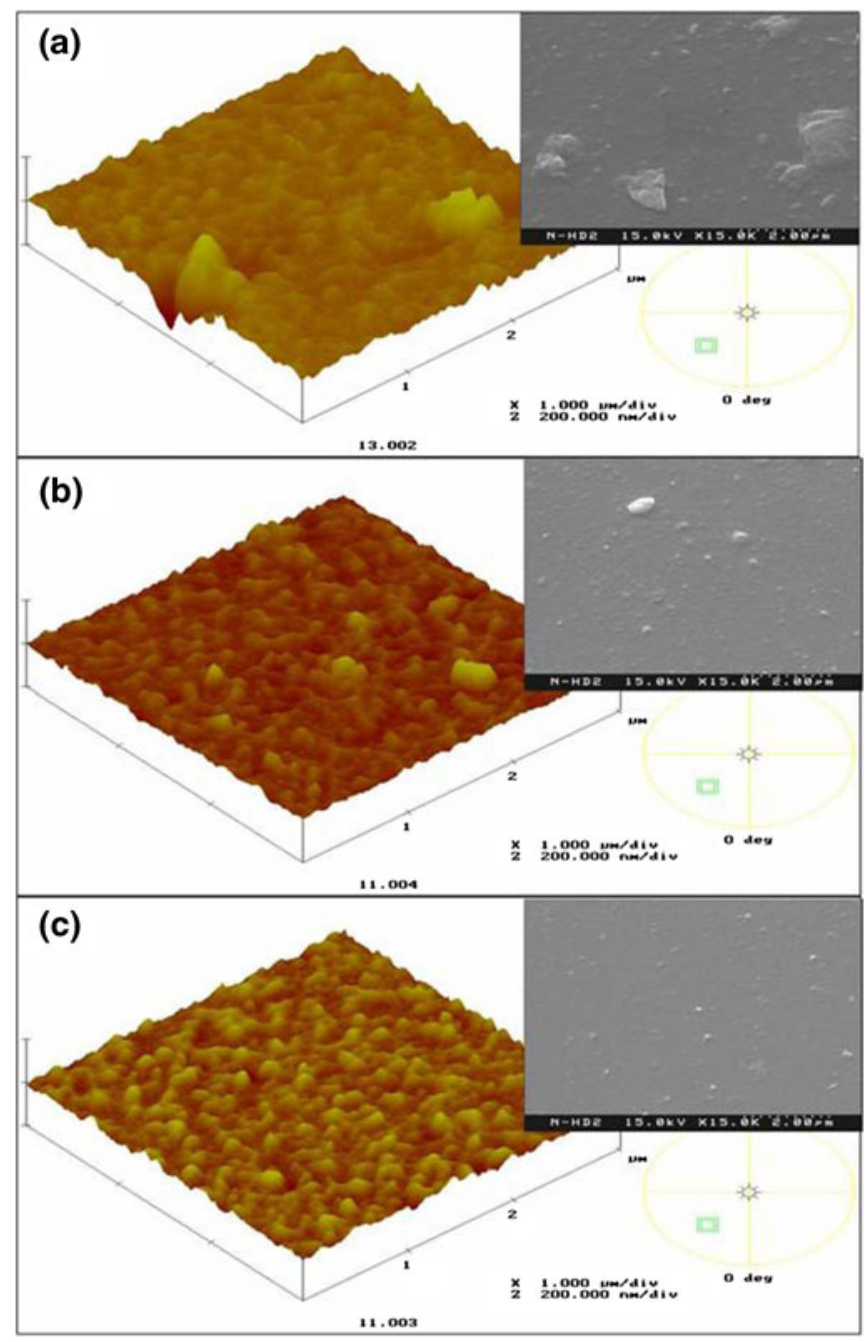

Figure 3. Surface roughness (AFM-3D) and SEM (inserts) images of ITO/PEDOT:PSS/ (PCBM/MEH:PPV) active layers with: (a) untreated, (b) oxygen-plasma treated and (c) nitrogen-plasma treated ITO.

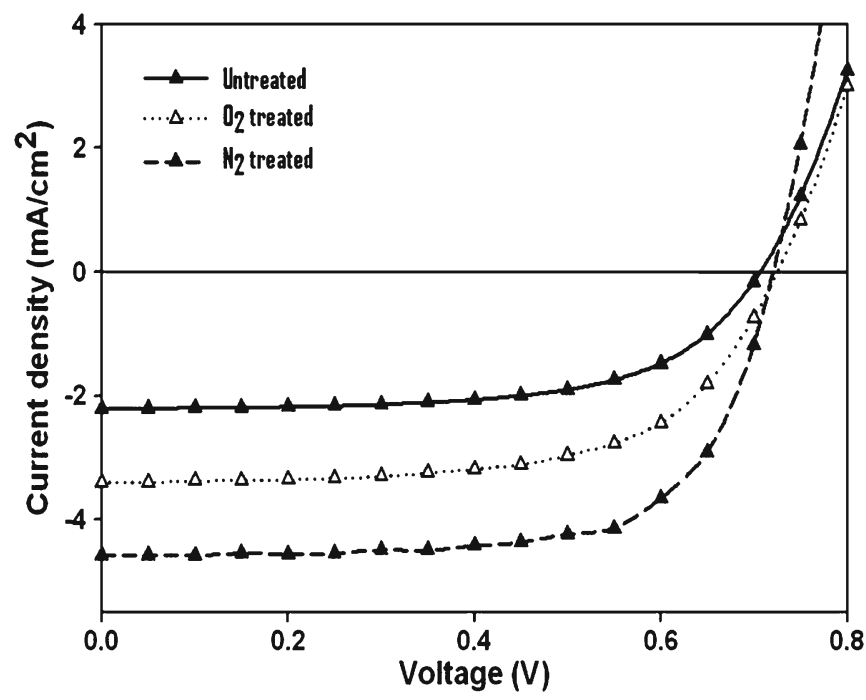

Figure 4. $I-V$ curves of ITO/PEDOT:PSS/ (PCBM/MEH:PPV) /Al solar cells.
Table 2. Performances of photovoltaic devices.

\begin{tabular}{lcccc}
\hline & $V_{\mathrm{oc}}(\mathrm{V})$ & Fill factor & $J_{\mathrm{sc}}\left(\mathrm{mA} / \mathrm{cm}^{2}\right)$ & Efficiency $(\eta \%)$ \\
\hline Untreated & 0.7 & 0.6 & 2.2 & 0.96 \\
$\mathrm{O}_{2}$ treated & 0.7 & 0.61 & 3.4 & 1.5 \\
$\mathrm{~N}_{2}$ treated & 0.7 & 0.7 & 4.59 & 2.25 \\
\hline
\end{tabular}

This treatment was used to produce an ITO anode for a hybrid solar cell that could consistently give $2.25 \%$ power conversion efficiency.

\section{Conclusions}

A new method for improving the performance of hybrid solar cells is proposed. ITO surfaces modified by $\mathrm{N}_{2}$ plasma treatment can significantly enhance the power conversion efficiency of a device in terms of it having improved open circuit voltage, short circuit current density, and fill factor (FF). Efficiency was also improved by reducing contact angle and decreasing the ITO's surface roughness.

\section{Acknowledgements}

This work was supported by the Ministry of Knowledge Economy (MKE) and the Korea Institute for Advancement of Technology (KIAT) through the Regional Innovation Centre for Solar Cell \& Module at Yeungnam and Human Resources Development Program (R\&D Workforce Cultivation Track for Solar Cell Materials and Process) of Korea Institute of Energy Technology Evaluation and Planning (KETEP) grant funded by the Korean Ministry of Knowledge Economy.

\section{References}

Afre R A, Hayashi Y and Soga T 2009 J. Phys. D: Appl. Phys. 42 042002

Ayzner A L, Wanger D D, Tassone C J and Tolbert S H 2008 J. Phys. Chem. C112 18711

Breeze A J, Schlesinger Z, Carter S A and Brock P J 2001 Phys. Rev. B64 125205

Deng X Y, Zheng L P, Mo Y Q, Yu G, Yang W, Weng W H and Yong C 2001 Chin. J. Polym. Sci. 19597

Gur I, Fromer N A, Chen C P, Kanaras A G and Alivisatos A P 2007 Nano Lett. 7409

Jeong C H, Lee J H, Lim J H, Lim J T and Yeom G Y 2006 Jap. J. Appl. Phys. 452788

Jin S H, Naidu B V K, Jeon H S, Park S M, Kim S C, Lee J W and Gal Y S 2007 Sol. Energy Mater. Sol. Cells 911187

Kim J S, Park J H, Jo J, Kim D Y and Cho K 2007 Appl. Phys. Lett. 91112111

Kim J Y, Lee K, Coates N E, Moses D, Nguyen T Q, Dante M and Heeger A 2007 Science 317222

Kim S Y, Hong K, Son J H, Jung G H, Lee J L, Choi K H, Song K H and Ahn K C 2008 Jap. J. Appl. Phys. 47862 
Kim Y W, Monroe M L, Seol J, Truong N T N, Cho S M, Anderson T J and Park C 2008 Korean J. Chem. Eng. 251036

Koetniyom W, Keawprajak A, Piyakuwat P, Pratontep S and Asawapirom U 2010 J. Microsc. Soc. ThaiLan 2447

Li G, Shrotriya V, Huang J, Yao Y, Yang Y 2005 J Appl. Phys. 98 043704
Reyes M R, Kim K, Dewald J, Sandoval R L, Acadhanula A, Curran S and Carroll D L 2005 Org. Lett. 75749

Tang A, Teng F, Wang Y, Huo Y, Han W, Yi L and Gao M 2008 Nanoscale. Res. Lett. 3502

You Z Z and Dong J Y 2006 J. Colloid Interf. Sci. 300819 